\title{
O CONCEITO BERMANIANO DE “ESTRANGEIRO” SOB O PRISMA DA TRADUÇÃO PÓS-COLONIAL ${ }^{1}$
}

\author{
BERMAN'S TRIALS OF THE FOREIGN AND POSTCOLONIAL TRANSLATIONS
}

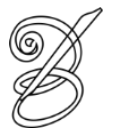 \\ Paul BANDIA* \\ Concordia University, Canada \\ Traduzido por: \\ Andressa Franco OLIVEIRA** \\ Universidade Estadual Paulista Júlio de Mesquita Filho, Brasil \\ Maria Angélica DEÂNGELI ${ }^{* * * *}$ \\ Universidade Estadual Paulista Júlio de Mesquita Filho, Brasil
}

\begin{abstract}
Resumo: O conceito bermaniano de "a prova do estrangeiro" é particularmente capaz de elucidar e explicar a prática tradutória pós-colonial. A escrita literária em línguas europeias na África é caracterizada pela vernaculização e pela diglossia literária como estratégia de escrita em um contexto de comunicação intercultural. O emprego de línguas coloniais suscita questões de identidade e de ideologia, assim como o problema das relações de poder entre o centro e a periferia. A estratégia de desterritorialização e de reterritorialização, frequentemente utilizada por escritores pós-coloniais para tentar se reapropriar da língua colonial e reivindicar seu espaço próprio, é um exemplo do que Berman chama de "a escrita-de-tradução". Esse estilo de escrita tem fundamentos ideológicos e socioculturais e coloca questões importantes relativas às escolhas tradutórias, questões às quais apenas se pode esperar responder por meio de uma ética séria e global da tradução. As teorias pós-modernas podem contribuir para a definição de um quadro ético da tradução que permite se distanciar da dicotomia presente na base de grande parte das teorias em tradutologia e que opõe a tradução estrangeirizadora à tradução domesticadora.
\end{abstract}

Palavras-chave: Antoine Berman. Pós-colonialismo. Teorias pós-modernas. Vernaculização literária. Ética da tradução.

\begin{abstract}
Antoine Berman's concept of "the trial of the foreign" has proven particularly useful inelucidating and accounting for postcolonial translation practice. African European-language writing is characterized by the practice of vernacularization and literary diglossia as a writing strategy in what is generally an intercultural communication context. This raises questions of identity and ideology with respect to the use of colonial languages, as well as issues of power relations between the center and the periphery. The strategy of deterritorializing and reterritorializing often used by postcolonial writers as an attempt to reappropriate the colonial language and thus claim their own space is an example of what Berman refers to as "writing as translation”. This style of writing, heavily grounded in ideological as well as sociocultural considerations, raises some serious questions about translation choices which can only be addressed through a sound and comprehensive ethics of translation. Postmodern theories can help us define an ethics framework for translation which will allow us to move away from the binary opposition, or the dichotomy, of foreignist versus domesticating translation that has been at the basis of much theorizing in translation studies.
\end{abstract}

Keywords: Antoine Berman. Postcolonialism. Postmodern theories. Vernacularization. Ethics of translation.

RECEBIDO EM: 8 de novembro de 2019

ACEITO EM: 17 de dezembro de 2019

PUBLICADO EM: janeiro de 2020 


\section{O CONCEITO BERMANIANO DE “ESTRANGEIRO” SOB O PRISMA DA TRADUÇÃO PÓS-COLONIAL}

\section{Introdução}

$\mathrm{N}$

osso interesse pelas teorias bermanianas deve-se principalmente à aplicação de algumas de suas hipóteses tradutológicas fundamentais. Referimo-nos

intercultural e à sua abordagem literalista que defende um ideal de transferência intercultural em que o Estrangeiro é acolhido como "estrangeiro" (1985, p. 68) e em que a estranheza (ou a estrangeiridade) do texto-fonte é posta em evidência. Evocamos, algumas vezes, em nossa pesquisa, esse aspecto da teoria bermaniana a fim de esclarecer o fenômeno de "traduçãoescrita" praticado pelos autores africanos que escrevem em línguas europeias em um contexto pós-colonial.

\section{A virada cultural}

O conceito de alteridade, próprio do domínio dos estudos culturais, pode fazer parte da tradutologia, se a tradução for considerada como uma forma de prática linguística e cultural que define e situa o Outro em um quadro fixo. Apenas recentemente, em tradutologia, o conceito do Outro cultural, questionando a traduzibilidade cultural, foi aprofundado. Na abordagem desconstrucionista, qualquer forma de crítica do texto, fundamentada em uma oposição binária, era suspeita de pré-conceito ideológico. Além disso, a criação de uma fronteira estável entre o Eu e o Outro resulta em uma "essencialização" da diferença cultural. No âmbito da tradutologia, o conceito de intertextualidade pode ser interpretado como o resultado de transações entre culturas já marcadas pelo pluralismo.

Tanto na etnografia quanto na tradução propriamente dita, o Outro cultural não é verbalizado de maneira direta. Ao contrário, ele é selecionado, adaptado e verbalizado de forma indireta, mediante a consciência do etnógrafo ou do tradutor. O vínculo reconhecido entre a textualização e a conceitualização da cultura provocou uma espécie de "crise de representação" em vários domínios, tais como a historiografia, os estudos literários e a etnografia. O debate "Escrita-Cultura" (writing-culture) resulta de uma concepção da cultura como texto, desenvolvida pela antropologia interpretativa. Ele permite se debruçar sobre os aspectos ligados ao processo e à produção da tradução. Os partidários da posição "Escrita- 
Cultura" defendem uma visão da cultura como constituída de códigos e representações. Dessa forma, a noção de tradução cultural foi ampliada. A tradução não é mais limitada à transferência entre o Eu e o Outro cultural, mas possui, também, um papel de regulador cultural, como é o caso, por exemplo, no contexto colonial, em que ela adquiriu um valor funcional.

As questões de representação cultural são tratadas pelas abordagens etnográficas em tradução. Essas permitem explorar as relações de poder entre determinadas culturas e identificar essas relações em um contexto inter e intra-cultural. Graças a essa "virada cultural" (cultural turn), constatou-se que a cultura não pode mais ser considerada como uma entidade estável, mas que se trata de um processo dinâmico em cujo cerne operam a diferença e o inacabado e, consequentemente, a negociação e a performance. A tradução, portanto, não se limita mais à transferência "entre culturas", mas, a partir do momento em que ela é vista como uma fusão cultural, ela pode ser considerada, também, como a fonte de novos espaços culturais (a cultura como fenômeno de tradução / culture as translation). A tradução, no entanto, não serve para confirmar as fronteiras e afirmar a dicotomia entre o centro e a periferia, mas cria, ao contrário, vários centros plurais nos quais são negociadas as diferenças culturais.

\section{A vernaculização e a diglossia literária}

A escrita africana de expressão europeia é, em grande parte, resultado de tais negociações das diferenças culturais entre a tradição oral africana e sua contrapartida europeia, o discurso narrativo oral. A literatura euro-africana é caracterizada por formações híbridas que misturam tradições autóctones e ocidentais. Essa variedade de escrita póscolonial é resultado de um tipo de "bilinguismo radical" (MEHREZ, 1992, p. 120-138) que evoca simultaneamente duas culturas linguísticas estrangeiras e distantes. Assim, pode-se dizer que as literaturas euro-africanas são, por si só, traduções, no sentido amplo do termo, que podem ajudar a esclarecer o impacto da tradução em uma cultura-fonte colonizada, e, posteriormente, em uma cultura linguística metropolitana que se revela homogeneizante. Além disso, pode-se, também, ressaltar o papel da tradução na criação de variedades africanas das línguas europeias.

No contexto pós-colonial, o escritor africano é, frequentemente, um sujeito bilíngue e bicultural que tem um bom domínio de sua língua africana e de sua língua europeia de escrita. Essa característica de mestiçagem cultural no escritor africano manifesta-se em sua obra por 
meio de uma diglossia linguística e literária que põe em evidência as relações de poder entre a língua e a cultura do "colonizado" e a língua e a cultura do "colonizador". Do ponto de vista sociolinguístico, o contato entre essas línguas e essas culturas rivais ou distantes suscita a questão de suas relações de força e de seus efeitos sobre os falantes. Em um nível psicolinguístico, as problemáticas apresentadas são as motivações ligadas ao emprego de tal ou tal código e as relações de desejo ou de repulsa ligadas ao emprego de tal ou tal idioma. Além disso, essa forma de diglossia literária evoca, também, a questão da identidade do texto, de sua nacionalidade literária, de sua geografia linguística ou da construção de sua territorialidade referencial.

O paradoxo aparente dessa escrita diglóssica é que todas as operações de territorialização cultural são feitas pela mediação de uma desterritorialização da língua e da cultura do Outro, pois uma língua estrangeira não se toma impunemente emprestada, cada língua portando em si mesma, como sabemos, sua própria visão de mundo. Ao elaborar práticas estéticas que desconstroem e exploram as normas linguísticas e literárias da língua colonial, vários escritores africanos criam estratégias de resistência à alienação linguística e cultural, "organizam espaços nos quais se refrata sua identidade literária, cultural e étnica" (TINE, 1995, p. 82, tradução nossa) ${ }^{2}$. Esses fenômenos de desconstrução e de exploração da língua colonial pelas línguas e culturas africanas realizam-se por meio da interferência linguística, da representação codificada do discurso e da narrativa de tradição oral. Essa vernaculização da literatura africana em língua europeia se faz pela elaboração e utilização de um "código do Eu" em oposição a um "código do Outro", este último constituindo a particularidade da literatura metropolitana ocidental. Os escritores africanos que recorrem à vernaculização da língua europeia ou colonial dedicam-se a uma prática estética que estabelece estreitas relações enunciativas, narrativas e intertextuais com a tradição oral da cultura africana. Suas obras são marcadas por uma desterritorialização referencial. Em outras palavras, a língua colonial é desterritorializada geograficamente e, também, com relação aos seus referentes históricos e literários.

\section{A contribuição bermaniana}

Alioune Tine define a vernaculização literária como "conjunto de procedimentos escriturais, narrativos, enunciativos e pragmáticos que especificam no texto francês os sinais de pertencimento e de reconhecimento linguístico, cultural e étnico do autor (e do leitor)" (TINE, 1995, p. 87, tradução nossa) ${ }^{3}$. E é efetivamente nesse nível da vernaculização literária 
que intervêm essas noções de cunho bermaniano que julgamos pertinentes para nosso estudo da tradução/transliteração/transposição praticada pelos escritores africanos. Em sua obra $L a$ traduction et la lettre ou l'auberge du lointain ${ }^{4}$, Berman (1985, p. 35-150) analisa a importância da tradução literal como estratégia que leva em consideração a alteridade do texto-fonte, seus sistematismos e sua estranheza. A concepção bermaniana de tradução literal rejeita qualquer tentativa de anexação, apropriação ou aclimatação do texto-fonte por uma visada etnocêntrica da tradução. Berman opõe uma visada ética positiva da tradução (ou seja, a estrangeiridade, o descentramento, a abertura para o Outro) a uma visada negativa da tradução (ou seja, uma tradução domesticadora, um etnocentrismo, uma hipertextualidade). De acordo com Berman, essa visada negativa da tradução só pode produzir uma tradução ruim que, "geralmente sob o pretexto da transmissibilidade, opera uma negação sistemática da estranheza da obra estrangeira" (1984, p. 17, tradução nossa) ${ }^{5}$. Uma tradução etnocêntrica levaria ao "sofrimento [...] o do texto traduzido. Aquele do sentido privado de sua letra" (BERMAN, 1985, p. 59, tradução nossa) ${ }^{6}$. Com relação a isso, Berman cita Jacques Derrida que escrevia em 1967: "um corpo verbal não se deixa traduzir ou transportar em uma outra língua. É precisamente isso que a tradução deixa de lado. Deixar de lado o corpo, essa é a própria energia essencial da tradução” (DERRIDA, 1967, p. 312, tradução nossa) ${ }^{7}$. Berman responde que "o que é negado - o corpo - se vinga. A tradução descobre ao seu próprio custo que letra e sentido são, ao mesmo tempo, dissociáveis e indissociáveis" (1985, p. 59, tradução nossa $)^{8}$. Além disso, não são todos os aspectos da forma que podem ser traduzíveis. Cada obra de arte possui aspectos intraduzíveis que asseguram sua "autoafirmação" (1985, p. 60).

Ao nos reconciliarmos com o que Berman chama de "aderência obstinada do sentido à letra" (1985, p. 54, tradução nossa $)^{9}$, podemos apreciar as técnicas, tais como a transliteração e a transposição utilizadas pelos escritores africanos em sua prática do neoliteralismo (no sentido bermaniano) e na representação do pensamento africano em língua europeia. A vernaculização do francês ou do inglês por esses escritores é fundada em estratégias literais de tradução que visam restituir a estranheza do texto "africano", acentuando sua especificidade cultural e linguística.

A vernaculização como estratégia de produção e de estilização da literatura póscolonial apoia-se em certas motivações sociológicas e político-ideológicas por parte do escritor que é, ele mesmo, um sujeito pós-colonial. Essa vernaculização manifesta-se por meio de marcas linguísticas distintas que são utilizadas para desterritorializar o francês para, em seguida, reterritorializá-lo em seu novo contexto pós-colonial. Uma das questões que suscita 
essa diglossia literária é a de saber como codificar, estilizar ou "literalizar", em língua francesa ou inglesa, um diálogo produzido em língua africana em um contexto tradicional. Qual tipo de estratégia enunciativa é preciso adotar para preservar a forma de representação da enunciação do discurso tradicional africano em francês (ou em inglês)?

Além disso, podemos nos interrogar sobre as motivações ligadas à produção desse texto que apresenta características de alteridade. Inicialmente, a língua de escrita literária, que é a língua dominante em todos os sentidos políticos, está sujeita literalmente aos imperativos de uma construção da identidade do sujeito pós-colonial. Assim, ao domínio reconhecido, de fato, da língua colonial, o autor opõe uma primazia fundada no desejo de escrever sua própria língua. Uma primazia psicolinguística de sua língua opõe-se a uma primazia sociopolítica da língua colonial.

O escritor africano encontra-se diante de um dilema. Afinal, como conciliar os imperativos de uma reivindicação da autenticidade cultural, linguística e étnica com o uso de um mecanismo linguístico estrangeiro? A vernaculização como estratégia de produção e de estilização da literatura é, para tais escritores, uma manifestação dos valores anticolonialistas 210 de resistência e contestação. Esses escritores são tradutores-intérpretes de sua própria realidade linguística e cultural. Dessa forma, o escritor africano cria espaços textuais trilhados pela vernaculização. É nesses espaços que se produzem o código do eu, a alteridade, e, também, que o autor e seu público se reterritorializam. Esses espaços (the spaces in-between) são investidos de um código mestiço do $\mathrm{Eu}$ e do Outro, com o objetivo de resistir à hegemonia linguística da língua colonial, opondo-se a tendências anexionistas e etnocêntricas de um projeto de tradução domesticador ou orientado para a cultura-alvo. Esse código mestiço (ou híbrido) elimina a distância linguística e cultural imposta pela língua estrangeira, entre o escritor e seu público africano. Por essa razão, ele converte-se em um código de proximidade linguística e cultural. O público estrangeiro encontra-se “desenraizado" e, até mesmo, desterritorializado por esse procedimento de vernaculização literária ou de tradução (neo)literal que, por vezes, pode ameaçar a legibilidade dos textos. No entanto, os escritores africanos, em geral, procuram evitar um literalismo muito radical que conduziria, por sua vez, a um etnocentrismo passível de produzir uma reação de rejeição e de fechamento em si mesmo (no sentido bermaniano) por parte do leitor estrangeiro. 


\section{A ética da diferença}

Para compreender a escolha pela vernaculização literária praticada pelos escritores africanos, seria preciso recuperar o conceito de eticidade em Berman. “A eticidade [...] reside no respeito, ou melhor, em um certo respeito pelo original" (1995, p. 92, tradução nossa) ${ }^{10}$. Respeitar a alteridade do texto não implica nem "o aniquilamento" do tradutor nem o apego "servil" à letra (1995, p. 93, tradução nossa $)^{11}$. Trata-se de evitar qualquer forma de 'manipulação do original que terá como único objetivo satisfazer as exigências da língua e da cultura-alvo. A formulação atenuante de "um certo respeito pelo original", proposta por Berman, orienta-nos para um conceito da tradução que não é nem inteiramente voltada para a fonte nem inteiramente voltada para o alvo, baseada em uma ética da tradução que leva em consideração a especificidade do original sem, no entanto, comprometer a legibilidade do texto-alvo ou a comunicabilidade da textualidade do original. Trata-se de uma tradução que encontra seu lugar no espaço literário da língua/cultura receptora, mas que, enquanto reflete a poeticidade de uma tradução e a posição tradutória do sujeito que traduz, ela apresenta sua diferença sem constrangimento e sem atrito.

\section{0 eco pós-modernista americano}

O conceito ético da tradução, de Antoine Berman, é retomado nas obras de Philip E. Lewis (Vers la traduction abusive ${ }^{12}$ ) e Lawrence Venuti (The Translator's Invisibility, autores que partilham de uma ética da diferença no que concerne ao respeito à alteridade na representação do traduzir. O título do artigo de Lewis baseia-se nesse comentário feito por Jacques Derrida em Le retrait de la métaphore: "Uma boa tradução deve sempre abusar". De acordo com Lewis, a tradução abusiva não respeita nem o funcionamento da língua-fonte, nem o da língua-alvo. A estratégia abusiva do ato de traduzir consiste na modulação comedida do texto de partida bem como do texto de chegada com o objetivo de introduzir uma mudança sensata ao texto com relação às expectativas do público-alvo no que se refere ao sentido, ao tom e à materialidade do texto. Nessa ótica, o projeto tradutório privilegia o trabalho sobre os segmentos textuais que contêm a "energia" do texto. Trata-se de uma tradução forte que dá lugar à "experimentação" e que busca respeitar a polivalência (polyvalencies) e a plurivocidade (plurivocities) do original. Tal estratégia de tradução liberta, desse modo, o sujeito que traduz da dominação da dualidade clássica fonte/alvo e dá liberdade para o seu potencial de criatividade reforçando, assim, sua posição tradutória.

Em sua busca de uma ética da tradução, Lawrence Venuti $(1995 ; 1998)$ propõe uma 
ética da diferença e uma ética da posição tradutória "Ethics of location" que se unem à tese de Berman, ainda que sejam mais orientadas para uma estratégia de resistência e de dissidência. A obra de Berman (L'Épreuve de l'étranger ${ }^{13}$, 1984) baseia-se na teoria da estranheza do romântico alemão Schleiermacher, que inspirou a própria obra de Venuti. Schleiermacher, como sabemos, diferencia dois métodos de tradução: por um lado, pode-se conduzir os leitores ao autor; por outro, pode-se conduzir o autor aos leitores. Berman apoia-se nessa concepção para elaborar uma ética do traduzir visando combater o etnocentrismo na tradução. Berman, assim como Venuti, aborda a problemática da posição tradutória do tradutor e concebe o ato de traduzir como uma intervenção ativa e crítica por parte do tradutor. Também define a problemática da tradução etnográfica no âmbito de sua análise do fenômeno do estrangeiro na tradução: um vínculo precursor que se revelou fundamental para os pensamentos pós-coloniais e pós-modernos em tradutologia, nos anos 90.

Enquanto Berman chama atenção para os aspectos éticos da tese de Schleiermacher insistindo na abertura para o estrangeiro, Venuti adota uma posição mais crítica que evidencia o elitismo e o nacionalismo prussiano de Schleiermacher, conferindo, dessa forma, uma

212 visada mais política do que ética a seus trabalhos. Para Venuti, a tese de Schleiermacher abre caminho para uma concepção da tradução como um meio de ação política e cultural. O conceito de estranheza em Venuti difere daquele de Schleiermacher, ou de Berman, no sentido de que para Venuti a estranheza mantida em uma tradução não depende só da culturafonte, mas poderia derivar, também, da cultura-alvo. Em outras palavras, a estranheza também faz referência aos elementos da cultura receptora que são, frequentemente, marginalizados ou estigmatizados. Esses elementos são suscetíveis de chamar a atenção do leitor para a textualidade da obra a ser traduzida e para o processo de sua produção. Além disso, eles nos lembram da diferença inerente às diversas línguas e às diversas culturas, e nos levam à problemática da traduzibilidade.

\section{Sinais de resistência e de dissidência}

O conceito de "resíduo" (the remainder) emprestado de Jean-Jacques Lecercle (1990) é de fundamental importância para Venuti, que utiliza o termo para descrever a multiplicidade de sentidos suscetíveis de ultrapassar, e até mesmo de obstruir, o uso transparente da língua (VENUTI 1995, p. 216). O "resíduo" é, frequentemente, imprevisível e incontrolável, mas deve ser apreendido e empregado na representação do traduzir. O conceito de "resíduo" em Venuti aproxima-se das noções de rastro e de suplementaridade em Derrida (1972), segundo as quais 
cada signo contém "rastros" de todas as significações que lhe foram atribuídas nos diferentes contextos. Para Venuti, a noção de "suplementaridade" refere-se ao fato de que a tradução pode funcionar como "suplemento" do original que, às vezes, precisa ser compensado ou substituído. Nesse sentido, longe de ser uma simples soma, a tradução é requerida pelo original a fim de preencher uma lacuna.

\section{7 À procura de uma terceira via}

\subsection{Uma via de negociação}

Venuti concebe o ato de traduzir como uma prova na qual o tradutor negocia as diferenças culturais e linguísticas do texto de partida à luz de um conjunto de diferenças provenientes da língua/cultura-alvo a fim de facilitar ou assegurar a recepção do estrangeiro nessa mesma cultura. Desse modo, na representação do traduzir, o texto estrangeiro encontrase investido de significações e características provenientes da língua/cultura receptora. A inserção de elementos da língua/cultura-alvo no texto-fonte está no centro das preocupações de teóricos como Berman e Venuti que propõem uma reflexão ética do traduzir visando conservar a estranheza do texto-fonte.

\subsection{0 paradoxo}

Entretanto, o paradoxo da abordagem de ambos reside no fato de que toda ética destinada a combater a inserção da língua/cultura-alvo no texto original só pode ser formulada ou praticada pelo viés da língua/cultura-alvo (seu estilo, seus dialetos, seus diferentes registros de discurso, etc.). Isso quer dizer que a especificidade linguística e cultural do original só pode ser assinalada de maneira indireta, por seu "deslocamento" na tradução, mediante uma diferença inserida nos valores e nas instituições da língua/cultura-alvo. Assim, a tradução, por definição, permanece assimiladora e ofusca a heterogeneidade e a hibridez inerentes a determinados textos.

\subsection{Uma terceira via (The in-between)}

Venuti, ao propor uma abordagem essencialmente estrangeirizadora, reconhece que toda tradução é por definição assimiladora (até mesmo a tradução estrangeirizadora), uma vez que em toda tradução os elementos do texto de partida são assimilados na cultura da línguaalvo. Todavia, para Venuti, as traduções estrangeirizadoras são inevitavelmente menos assimiladoras que as traduções domesticadoras. Encontramos elementos estrangeirizadores 
em uma tradução domesticadora, assim como elementos domesticadores em uma tradução estrangeirizadora. A diferença fundamental entre as duas abordagens reside no fato de que a tradução domesticadora tende a ocultar ("naturalizar") os traços característicos da línguafonte, ao passo que a tradução estrangeirizadora tem por missão acentuar os elementos provenientes do texto-fonte.

\subsection{Um desvio infiel (“Bypassing fidelity”)}

Os méritos da ética da diferença que constitui o fundamento de toda reflexão sobre a tradução para os teóricos defensores da estrangeirização (source-oriented), nesse caso Berman, Venuti e Lewis, estão baseados no fato de que essas estrangeirizações (foreignists) não se deixam limitar pela noção de fidelidade que parece constituir o ponto de partida de toda reflexão ética sobre a tradução. Embora a origem da tradução e, em certa medida, a posição tradutória do sujeito que traduz permaneçam primordiais em suas reflexões, sua ética da diferença não está, de forma alguma, baseada em qualquer (re-)interpretação da noção de fidelidade. A reflexão acerca da ética na tradução deve ir além das considerações de

214 fidelidade ou de lealdade perante o texto-fonte, os clientes ou o público-alvo, a fim de se situar num contexto maior de troca cultural. Venuti, por exemplo, procura minimizar a oposição binária entre tradução estrangeirizadora (foreignizing translation) e tradução domesticadora (domesticating translation), para evitar o problema da fidelidade. Segundo Venuti, a realização de toda tradução passa, inevitavelmente, pela implementação das duas estratégias. Além disso, levando em conta as exigências linguísticas e culturais do ato de traduzir, o sujeito que traduz nem sempre pode escolher entre uma abordagem exclusivamente domesticadora ou exclusivamente estrangeirizadora, embora seja evidente que, por diversas razões subjacentes ao seu projeto tradutório, ele possa direcionar sua tradução a um ou outro desses polos. Em outras palavras, de maneira oposta a Schleiermacher, que insiste nos méritos de uma tradução estrangeirizadora a serviço de seu projeto nacionalista e que recusa, categoricamente, o surgimento de uma terceira via, Venuti parece minimizar a dicotomia imposta pela oposição binária clássica em benefício de uma terceira via, a via do centro (textual middles), caracterizada por níveis variáveis de prática domesticadora ou estrangeirizadora. Trata-se da fusão de duas tendências que estão, na verdade, sempre presentes e são confundidas em todo ato de tradução, independentemente do projeto tradutório e da abordagem privilegiada pelo sujeito tradutor. Há sempre um resquício de estrangeirização em uma tradução domesticadora e de domesticação em uma tradução 
estrangeirizadora. De fato, uma tradução que não é nem totalmente estrangeirizadora nem totalmente domesticadora poderá se conformar às expectativas intuitivas do público-alvo sem, no entanto, "silenciar" as especificidades linguísticas e culturais do texto de partida que constituem sua própria energia. A via do centro leva-nos a uma tradução que reflete elementos característicos da língua/cultura-fonte inscrevendo-se no espaço literário da cultura receptora.

\subsection{A virada em direção ao centro e o pós-colonialismo}

É indispensável discutir os trabalhos dos estrangeirizadores americanos ${ }^{14}$, se quisermos medir o alcance do pensamento bermaniano na reflexão atual da tradutologia. A influência da teoria bermaniana manifesta-se no âmbito dos estudos pós-modernos em tradutologia, mais particularmente nos estudos pós-coloniais e nos estudos feministas. Cada vez mais, as teorias no campo da tradutologia orientam-se para o estudo da diferença, ao invés do estudo da semelhança. Essa transformação em favor da diferença abre caminho para uma abordagem de análise tradutológica que se revela não dicotômica ou não binária. Elementos de semelhança e de diferença coexistem em toda tradução, pois sempre há semelhança apesar da diferença e sempre há diferença apesar da semelhança. Essa nova abordagem que orienta a análise e a crítica tradutológica para uma terceira via, a do centro, revela-se particularmente esclarecedora no estudo do fenômeno da escrita-tradução (ou "escrita-da-tradução", BERMAN, 1995, p. 66) no contexto pós-colonial. Percebe-se um paralelo entre a definição dessa via do centro (textual middles) e a prática linguageira de hibridez, mestiçagem ou bilinguismo radical por parte dos escritores africanos. Longe de praticar um neoliteralismo abusivo, esses escritores adotam uma abordagem baseada na mistura de técnicas estrangeirizadoras e domesticadoras com a preocupação da legibilidade e aceitabilidade de sua representação do traduzir africano. As obras literárias africanas caracterizam-se pela intertextualidade nutrida por uma mistura da materialidade linguageira resultante da tradição oral africana e da experiência colonial. Essa literatura híbrida e mestiça é resultado do que Jean-Jacques Lecercle chama de "violência da língua" (The Violence of Language, 1990), na qual o "resíduo" (remainder) é irredutível, escapando a toda análise sintática ou semântica conforme a linguística normativa. Ela situa-se em um espaço de interculturalidade (the space inbetween, BНАВНА, 1994) e mantém sua estranheza inserindo-se no espaço literário da língua receptora colonial. Tomemos a título de exemplo um excerto do romance The Voice (1964) de Gabriel Okara, traduzido para o francês por Jean Sevry (La Voix, 1985): 
You asked me why I am giving you my hands in this happening-thing, when you have become the enemy of everything in the town? Well, I am giving you my hands and my inside and even my shadow to let them see in their insides that if even the people do not know, we, you and I, know and have prepared our bodies to stand in front of them and tell them so. They now feel that I really am a witch, so I put fear into their insides. That sweetened my inside because I had wanted to remain a witch in their eyes so that I could do something against them. Then you returned, and when I started to hear the happening-things in your name, my hopes rose to the eye of the sky. And then yesterday you came running, being pursued by the people. So I called you in. These are my answering words to your questioning words (OKARA, 1964, p. $56)^{15}$

Tradução para o francês:

Tu m'as demandé pourquoi je te prête main-forte en cette chose qui arrive au moment où en ville tout se dresse contre toi? Eh bien, je te prête main-forte et mon for intérieur et jusqu'à mon ombre pourqu'ils puissent voir en leur for intérieur que même si les gens ne savent pas, nous, toi et moi, nous savons et nous avons préparé nos corps à se dresser devant eux pour le leur dire. Maintenant, ils croient vraiment que je suis une sorcière, aussi je mets de la peur en leur for intérieur. Et cela a mis de la douceur en mon for intérieur puisque j'avais souhaité rester une sorcière à leurs yeux afin que je puisse faire quelque chose contre eux. Et puis tu es revenu, et lorsque j'ai commencé à entendre les choses qui se passaient en ton nom, mes espoirs sont montés jusqu'à l'oeil du ciel. Et puis hier tu es venu en courant, puisque les gens te poursuivaient. Alors je t'ai invité à entrer. Voilà les mots qui font réponse à tes mots qui faisaient question. ${ }^{16}$ (SEVRY, 1985, p. 48)

Evidentemente, esse excerto é menos transparente do que a maioria dos textos da literatura eurófona africana. Entretanto, trata-se de um texto híbrido que ilustra bem a intertextualidade característica de vários textos oriundos da África, que, dessa forma, se inserem no espaço literário anglófono. Com o intuito de aproximar o leitor do patrimônio cultural da obra (ou seja, a língua/cultura Ijaw, expressa em um texto em inglês), certa violência da língua se impõe e se manifesta por meio de uma estratégia de escrita desconstrucionista. Do ponto de vista da tradução, trata-se de um texto-fonte elaborado a partir de uma prática abusiva (LEWIS, 1985) que dá particular atenção à sequência de significantes, ao processo sintático, às relações discursivas e ao mecanismo da língua na construção e na representação do pensamento autóctone. O texto contém vários elementos de resíduo que constituem sua energia e chamam atenção para a sua materialidade linguageira. Esses elementos irredutíveis resistem a qualquer tentativa de assimilação, o que dificulta ainda mais a tarefa do tradutor que se encontra diante de um original oriundo de uma performance linguística já bastante complexa. Com esse reforço da dificuldade da tradução, os abusos linguageiros que acentuam a complexidade do texto tornam-se ao mesmo tempo incontornáveis e, até mesmo, necessários em um projeto de tradução. Como explica Lewis: 
A possibilidade real de tradução - a traduzibilidade que emerge no movimento de diferença como uma propriedade fundamental das línguas - aponta para um risco a ser assumido: o risco da tradução forte e poderosa que valoriza a experiência, modifica o uso, busca relacionar as polivalências ou plurivocidades ou realça a expressividade do original ao se realizar. (LEWIS apud VENUTI, 2000, p. 270, tradução nossa $)^{17}$.

De acordo com Lewis, esse tipo de tradução se realiza em três áreas: a língua do original, a língua de tradução e o espaço entre as duas. $\mathrm{O}$ exercício tem dois objetivos: "primeiro reproduzir o uso e o abuso do original na tradução e segundo suprir o que, de fato, não pode ser reproduzido com uma remobilização do uso e do abuso que qualifica ainda mais o original como usado e, portanto, abusado" (LEWIS apud VENUTI, 2000, p. 272, tradução nossa) ${ }^{18}$.

Os elementos de resíduo (the remainder) desse excerto reproduzem, de certa forma, os rastros de uma tradição oral expressa na língua colonial por expressões como "inside" (interior) traduzido por "for intérieur" (interior), "my shadow" (minha sombra) traduzido por "mon ombre" (minha sombra), "this happening-thing" (esse acontecimento-coisa) traduzido por "cette chose" (essa coisa), "I am giving you my hands" (eu estou te dando minhas mãos) traduzido por "Je te prête main-forte" (eu estou te dando uma mão), "that sweetened my inside" (isso adoçou meu interior) traduzido por "Et cela a mis de la douceur en mon for intérieur" (e isso adoçou meu interior), "These are my answering words to your questioning words" (essas são minhas palavras de resposta a suas palavras de pergunta) traduzido por "Voilà les mots qui font réponse à tes mots qui faisaient question" (essas são as palavras que formam resposta para as suas palavras que formavam pergunta). A tradução proposta por Jean Sevry respeita as múltiplas vozes e os diferentes registros do romance de Okara, sem, no entanto, comprometer sua legibilidade. Ao falar sobre a experiência de tradução dessa obra, Sevry diz o seguinte (principalmente com relação à técnica de repetição):

\footnotetext{
O ijaw é um sistema tonal; o inglês é uma língua acentuada. O arranjo das cadeias de superfície é fundamentalmente diferente tal como o sistema de verbos ou de gêneros. Os ideófonos são abundantes, o que permite que o locutor especifique infinitamente a expressão de suas sensações e das modalidades. Okara tenta expor esses procedimentos por meio de repetições duplas ou triplas que são apenas equivalências muito aproximativas; o que o tradutor buscará, por sua vez, restituir por meio de frases como: "Et maintenant tes cheveux sont noirs très noirs et plus noirs que le noir". Traduzir La Voix corresponde, de alguma forma, encontrar a escrita de Okara e passar pelos mesmos percursos de pesquisas (SEVRY, 1985, p. 6-7, tradução nossa $)^{19}$.
}

Sevry compartilha conosco a dificuldade inerente à tradução de um original que é, por 
si só, um texto híbrido, mestiço, o produto de um processo de escrita-tradução. Esse texto, cujo fundamento linguístico e cultural é suficientemente heterogêneo, resiste a qualquer tentativa de assimilação ou de literalização e recorre a uma estratégia de tradução que levará em conta sua especificidade material e características da língua/cultura receptora. Traduzir um original que é, de início, caracterizado por certa interculturalidade (ou intertextualidade) exige, portanto, uma abordagem que não seja nem exclusivamente domesticadora, nem exclusivamente estrangeirizadora, mas uma estratégia sensata que responda às exigências do projeto de tradução em um contexto maior de intercâmbio cultural. A vernaculização literária e a diglossia literária que caracterizam a obra literária africana estão no cerne da problemática da identidade, da ideologia e de relações de poder e de intercâmbio entre o centro e a periferia, entre a metrópole e seus satélites. Trata-se, provavelmente, da consequência direta do papel da história na produção literária.

\section{Conclusão}

Os trabalhos dos teóricos estrangeirizadores (foreignists) tais como Schleiermacher, 218 Berman e Venuti tiveram um grande impacto na pesquisa em tradutologia, mais particularmente no âmbito dos estudos pós-modernos, pós-coloniais e feministas. Entretanto, a fim de evitar a eterna oposição entre estrangeirizadores e domesticadores, convém explorar a possibilidade de uma terceira via, a via do centro (textual middles; the space in-between) suscetível de compreender diferenças (inerentes à língua e à prática literária) frequentemente negligenciadas, exageradas ou assimiladas, em qualquer ato de tradução que se apoia em teorias normativistas ou prescritivistas em tradutologia. Trata-se de elaborar teorias pósmodernas da ética da tradução a fim de, por um lado, confrontar a problemática do binário ou da dicotomia existentes na teorização e, por outro, atribuir à ética da diferença seu devido lugar e levar em conta questões acerca do posicionamento tradutório (translational position; ethics of location) e do contexto global de intercâmbio cultural.

\section{REFERÊNCIAS}

BERMAN, Antoine. L’Épreuve de l'étranger. Paris: Gallimard, 1984. (Essais).

BERMAN, Antoine. Les tours de Babel: essais sur la traduction. Mauvezin: Trans-europ repress, 1985.

BERMAN, Antoine. Pour une critique des traductions: John Donne. Paris: Gallimard, 1995. 
BHABHA, Homi K. The Location of Culture. London: Routledge, 1994.

DERRIDA, Jacques. L'écriture et la différence. Paris: Seuil, 1967.

DERRIDA, Jacques. Positions. Paris: Minuit, 1972.

LECERCLE, Jean-Jacques. The Violence of Language. London: Routledge, 1990.

LEWIS, Philip E. The Measure of Translation Effects. In: VENUTI, Lawrence. The Translation Studies Reader. London: Routledge, 1985. p. 264-283.

MEHREZ, Samia. Translation and the Postcolonial Expérience. In: VENUTI, Lawrence. Rethinking Translation. London: Routledge, 1992. p. 120-138.

OKARA, Gabriel. The Voice. London: Heinemann, 1964.

OKARA, Gabriel. La voix. Traduzido por: J. Sevry. Paris: Hatier, 1985.

TINE, Alioune. La diglossie linguistique et la diglossie littéraire et leurs effets dans la pratique esthétique d'Ousmane Sembène. In: TINE, Alioune. Littérature et cinéma en Afrique francofone: Ousmane Sembène et Assia Djebar. Paris: L'Harmattan, 1995. p. 8297.

VENUTI, Lawrence. The Translator's Invisibility: A History of Translation. London: Routledge, 1995.

VENUTI, Lawrence. The Scandals of Translation: Towards an Ethics of Difference. London: Routledge, 1998.

VENUTI, Lawrence. The Translation Studies Reader. London: Routledge, 2000.

\footnotetext{
${ }^{1}$ Tradução do artigo Le concept Bermanien de l' Étranger' dans le prisme de la traduction postcoloniale, escrito por Paul Bandia, originalmente publicado na revista TTR: traduction, terminologie, rédaction, em 2001. Disponível em: https://www.erudit.org/fr/revues/ttr/2001-v14-n2-ttr409/000572ar/. Acesso em: 3 jan. 2020. A tradução e a publicação deste artigo foram gentilmente autorizadas pelo autor, Prof. Dr. Paul Bandia, por e-mail, em 10 de janeiro de 2019, e pela diretora de publicação da revista TTR, Aline Francoeur, também por e-mail, em 26 de maio de 2019.

* Paul BANDIA - Doutor em Linguística e Mestre em Tradução pela Université de Montréal, Canadá. Graduado em Lettres modernes bilingues, Paris/Yaoundé, Camarões. É professor titular na Concordia University, Canadá. Montréal, Québec, Canadá.

Currículo acadêmico: https://www.concordia.ca/artsci/francais/faculty.html?fpid=paul-bandia

E-mail: paul.bandia@concordia.ca

*** Andressa Franco OLIVEIRA - Mestranda em Estudos Linguísticos e graduada em Letras com Habilitação de Tradutor (2017) pela Universidade Estadual Paulista Júlio de Mesquita Filho (Unesp), campus de São José do Rio Preto.

São José do Rio Preto, São Paulo, Brasil.

Currículo acadêmico: http://lattes.cnpq.br/2026973404756120

ORCID: https://orcid.org/0000-0002-5160-9460

E-mail: andressafrancooliveira@ gmail.com

**** Maria Angélica DEÂNGELI - Doutora em Letras (2010) pela Universidade Estadual Paulista Júlio de Mesquita Filho. Mestre em Didactologie des Langues et Cultures (1995) pela Université de La Sorbonne
} 
Nouvelle Paris III, França. Realizou maîtrise de Français Langue Étrangère (1994) e Certificat Didactique Français Langue Étrangère (1992) pela Université de La Sorbonne Nouvelle Paris III, França. Graduada em Letras com Habilitação de Tradutor (1990) pela Universidade Estadual Paulista Júlio de Mesquita Filho. É professora assistente na Universidade Estadual Paulista Júlio de Mesquita Filho.

São José do Rio Preto, São Paulo, Brasil.

Currículo acadêmico: http://lattes.cnpq.br/3428288938857306

ORCID: https://orcid.org/0000-0002-5181-1634

E-mail: angelica.deangeli@unesp.br

${ }^{2}$ Original:"qu'ils s'aménagent des espaces où se réfracte leur identité littéraire, culturelle et ethnique" (TINE, 1995, p. 82).

3 “L'ensemble des procédures scripturales, narratives, énonciatives et pragmatiques qui spécifient dans le texte français les signes d'appartenance et de reconnaissance linguistique, culturelle et ethnique de l'auteur (et du récepteur)" (TINE, 1995, p. 87).

${ }^{4}$ N. T.: A tradução e a letra ou o albergue do longínquo é o título do texto de Berman traduzido por MarieHélène Catherine Torres, Mauri Furlan e Andréia Guerini, e publicado pela Editora 7Letras, em 2007. Embora algumas obras citadas neste artigo tenham sido traduzidas para o português do Brasil, optamos por um trabalho de tradução livre dos excertos que figuram no texto.

5 "Généralement sous couvert de transmissibilité, opère une négation systématique de l'étrangeté de l'oeuvre étrangère" (1984, p. 17).

6 "Souffrance [...] celle du texte traduit. Celle du sens privé de sa lettre" (1985, p. 59).

7 "Un corps verbal ne se laisse pas traduire ou transporter dans une autre langue. Il est cela même que la traduction laisse tomber. Laisser tomber le corps, telle est même l'énergie essentielle de la traduction” (1967, p. 312).

8 "Ce qui est nié - le corps - se venge. La traduction découvre à ses dépens que lettre et sens sont à la fois dissociables et indissociables" (1985, p. 59).

2209 “L'adhérence obstinée du sens à sa lettre” (1985, p. 54).

11 "L'anéantissement", "servile" (1995, p. 93).

12 Título de uma comunicação apresentada na França em 1980 e publicada em inglês sob o título The Measure of Translation Effects.

${ }^{13}$ N.T.: A prova do estrangeiro é o título do texto de Berman traduzido para o português por Maria Emília Pereira Chanut e publicado pela editora EDUSC, em 2002.

${ }^{14}$ Assim como Philip E. Lewis, The Measure of Translation Effects (1985); Lawrence Venuti, 'Introduction', Translation and Minority (1998); Maria Tymoczko, Post-colonial writing and literary translation (1998); Tejaswini Niranjana, Siting Translation (1992); Eric Cheyfitz, The Poetics of Imperialism (1991).

15 Você me perguntou por que eu estou te dando minhas mãos nesse acontecimento-coisa, quando você se tornou o inimigo de tudo na cidade? Bem, eu estou te dando minhas mãos e meu interior e até mesmo minha sombra para deixá-los ver em seus interiores que se mesmo as pessoas não sabem, nós, você e eu, sabemos e preparamos nossos corpos para ficar de pé na frente deles e dizer-lhes isso. Eles agora acham que eu realmente sou uma bruxa, portanto eu ponho medo em seus interiores. Isso adoçou meu interior porque eu queria permanecer uma bruxa aos seus olhos para que eu pudesse fazer algo contra eles. Então você voltou, e quando eu comecei a ouvir os acontecimentos-coisa em seu nome, minhas esperanças se elevaram aos olhos do céu. E então ontem você veio correndo, sendo seguido(a) pelas pessoas. Então eu te convidei para entrar. Essas são minhas palavras de resposta as suas palavras de pergunta (OKARA, 1964, p. 56, tradução nossa).

${ }^{16}$ Você me perguntou por que eu estou te dando uma mão nessa coisa que está acontecendo no momento em que na cidade tudo está contra você? Bem, eu estou te dando uma mão e meu interior e até minha sombra para que eles possam ver em seus interiores que mesmo se as pessoas não sabem, nós, você e eu, sabemos e preparamos nossos corpos para se colocarem diante deles e dizer-lhes isso. Agora, eles acreditam realmente que eu sou uma bruxa, eu também ponho medo em seus interiores. E isso adoçou meu interior, pois eu tinha desejado permanecer uma bruxa aos seus olhos para que eu pudesse fazer algo contra eles. E depois você voltou, e quando eu comecei a ouvir as coisas que aconteciam em seu nome, minhas esperanças se elevaram até o olho do céu. E então ontem você veio correndo porque as pessoas estavam te perseguindo. E então eu te convidei para entrar. Essas são as palavras que formam resposta para as suas palavras que formavam pergunta (SEVRY, 1985, p. 48, tradução nossa).

17 "The real possibility of translation - the translatability that emerges in the movement of differrence as a fondamental property of languages - points to a risk to be assumed: that of the strong, forcefol translation that values expérimentation, tampers with usage, seeks to match the polyvalencies or plurivocities or expressive stresses of the original by producing its own" (VENUTI, 2000, p. 270).

BANDIA, Paul. O conceito bermaniano de "estrangeiro" sob o prisma da tradução pós-colonial. Belas Infiéis, Brasília, v. 9, n. 1, p. 205-221, 2020. Traduzido por: Andressa Franco OLIVEIRA, Maria Angélica DEÂNGELI. 
18 "First to reproduce the use and abuse of the original in the translation and second to supply for what cannot in fact be reproduced with a remobilization of use and abuse that further qualifies the original as used and thus abused" (VENUTI, 2000, p. 272).

19 "L'ijaw est un système tonal; l'anglais est une langue accentuée. L'arrangement des chaînes de surface est fondamentalement différent tout autant que le système des verbes ou des genres. Les idéophones abondent, ce qui permet au locuteur de nuancer à l'infini l'expression de ses sensations et des modalités. Okara s'efforce d'en rendre compte par des redoublements ou des triplements qui ne sont que des équivalences três approximatives; ce que le traducteur tentera à son tour de rendre par des phrases comme: 'Et maintenant tes cheveux sont noirs três noirs et plus noirs que le noir'. Traduire La Voix revient, en quelque sorte, à retrouver l'écriture d'Okara et à passer par les mêmes itinéraires de recherches" (OKARA, 1985, p. 6-7). 